\title{
Interreader Reliability of Liver Imaging Reporting and Data System Treatment Response: A Systematic Review and Meta-Analysis
}

\author{
Dong Wook Kim ${ }^{1}$, Sang Hyun Choi ${ }^{1, * \mathbb{D}}$, Ji Sung Lee ${ }^{2} \mathbb{D}$, So Yeon Kim ${ }^{1}$, So Jung Lee ${ }^{1}$ and Jae Ho Byun ${ }^{1}$ \\ 1 Department of Radiology and Research Institute of Radiology, University of Ulsan College of Medicine, Asan \\ Medical Center, Seoul 05505, Korea; fsnoruen@gmail.com (D.W.K.); sykim.radiology@gmail.com (S.Y.K.); \\ radiology97@amc.seoul.kr (S.J.L.); jhbyun@amc.seoul.kr (J.H.B.) \\ 2 Department of Clinical Epidemiology and Biostatistics, University of Ulsan College of Medicine, \\ Asan Medical Center, 88 Olympic-Ro 43-Gil, Songpa-Gu, Seoul 05505, Korea; totoro96a@gmail.com \\ * Correspondence: edwardchoi83@gmail.com; Tel.: +82-2-3010-1797
}

check for updates

Citation: Kim, D.W.; Choi, S.H.; Lee, J.S.; Kim, S.Y.; Lee, S.J.; Byun, J.H. Interreader Reliability of Liver Imaging Reporting and Data System Treatment Response: A Systematic Review and Meta-Analysis. Diagnostics 2021, 11, 237. https:// doi.org/10.3390/diagnostics11020237

Academic Editor: Jean-Francois

H. Geschwind

Received: 30 November 2020

Accepted: 1 February 2021

Published: 4 February 2021

Publisher's Note: MDPI stays neutral with regard to jurisdictional claims in published maps and institutional affiliations.

Copyright: (c) 2021 by the authors. Licensee MDPI, Basel, Switzerland. This article is an open access article distributed under the terms and conditions of the Creative Commons Attribution (CC BY) license (https:/ / creativecommons.org/licenses/by/ $4.0 /)$.

\begin{abstract}
Background: For a proper management strategy in patients with locoregionally treated hepatocellular carcinoma (HCC), it is essential that the Liver Imaging Reporting and Data System (LI-RADS) treatment response algorithm (LR-TR) has high interreader reliability. We aimed to systematically evaluate the interreader reliability of LR-TR and sources of any study heterogeneity. Methods: Original studies reporting the interreader reliability of LR-TR were identified in MEDLINE and EMBASE up to 20 September 2020. The pooled kappa coefficient ( $\mathrm{K}$ ) was calculated using the DerSimonian-Laird random effects model. Subgroup analyses were performed according to imaging modality (magnetic resonance imaging (MRI) or computed tomography (CT)). Meta-regression analyses were performed to explore study heterogeneity. Results: Eight studies with 851 HCCs were finally included. Pooled $\mathrm{k}$ was 0.70 (95\% CI, 0.58-0.82) for CT/MRI LR-TR, and those of MRI and CT were 0.71 (95\% CI, 0.53-0.89) and 0.71 (95\% CI, 0.65-0.78), respectively. Study design $(p<0.001)$ and type of treatment $(p=0.02)$ were significantly associated with substantial study heterogeneity. Conclusion: LR-TR showed substantial interreader reliability regardless of the imaging modality. Because of substantial study heterogeneity, which was significantly associated with study design and type of treatment, published values for the interreader reliability of LR-TR should be interpreted with care.
\end{abstract}

Keywords: computed tomography; hepatocellular carcinoma; interreader reliability; LI-RADS; liver; magnetic resonance imaging; meta-analysis; systematic review; treatment response

\section{Introduction}

Hepatocellular carcinoma (HCC) is the fifth most common type of cancer and the third leading cause of cancer-related deaths worldwide [1,2]. In the management of HCC, locoregional treatments, including local ablation, transarterial treatment, and external beam radiation therapy (EBRT), play major roles as curative, palliative, or bridging/downstaging therapies [3-6]. Multiphasic contrast-enhanced computed tomography (CT) and magnetic resonance imaging (MRI) are widely used to evaluate the response after locoregional treatment for HCC. Given the significant correlation between treatment response determined by CT or MRI and patient prognosis $[7,8]$, the accurate and reliable assessment of treatment response by an imaging test cannot be overemphasized.

The Liver Imaging Reporting and Data System (LI-RADS) introduced a treatment response algorithm in 2017 [9]. This provides a comprehensive approach to standardize the assessment of treatment response after locoregional treatments on contrast-enhanced CT or MRI. The LI-RADS treatment response algorithm (LR-TR) evaluates the presence of arterial-phase hyperenhancement, washout appearance, and enhancement similar to that 
at pre-treatment, and categorizes the treated observation into three categories according to its likelihood of viability, i.e., LR-TR viable, equivocal, or nonviable [9].

Notwithstanding the importance of the diagnostic performance, it is essential that the LR-TR has high interreader reliability if it is to be used for determining treatment response and deciding on a proper management strategy in patients with HCC. Prior studies have reported on the interreader reliability of the LR-TR [10-17], but their results are subject to limitations because of their relatively small sample sizes and between-study variability in the reported data. Given the increased attention to LR-TR in clinical practice, we consider it timely and important to determine the interreader reliability of LR-TR and to understand any differences among the published studies.

In this regard, we aimed to systematically evaluate the interreader reliability of LR-TR and explore the sources of any study heterogeneity.

\section{Materials and Methods}

This systematic review and meta-analysis was performed according to the Preferred Reporting Items for Systematic Reviews and Meta-Analyses (PRISMA) guidelines [18].

\subsection{Literature Search}

A systematic search of MEDLINE and EMBASE was conducted to identify original studies reporting the interreader reliability of the CT/MRI LI-RADS treatment response algorithm (LR-TR). The search query is described in Table A1. The bibliographies of the identified studies were explored to search for further eligible studies. As LR-TR was introduced in 2017, the literature search was performed on studies published from 1 January 2017 to 20 September 2020. The search was limited to English-language studies on human subjects.

\subsection{Eligibility Criteria}

Studies that met the following criteria were included: (a) population: patients who underwent locoregional treatment for HCC; (b) index test: multiphasic contrast-enhanced CT and/or MRI; (c) comparator: no comparator; (d) outcomes: interreader reliability of CT/MRI LR-TR. Studies were excluded if they were (a) reviews, conference abstracts, case reports/series, letters, editorials; (b) not in the field of interest; and (c) used a patient cohort that partially overlapped with other studies.

Two reviewers ( $\geq 5$ years of experience in abdominal imaging) first screened the titles and abstracts for potential eligibility, and then conducted full-text reviews of selected articles to determine their eligibility for the analysis. Disagreements between the reviewers were resolved by consensus.

\subsection{Data Extraction and Quality Assessment}

The following data were extracted from the eligible studies: (a) study characteristics: authors, year of publication, institution, country, duration of patient enrollment, study design (prospective vs. retrospective), and subject enrollment methods (consecutive vs. convenience); (b) patient characteristics: number of patients and HCCs, age, sex, cause of liver disease, locoregional treatment; (c) imaging analysis: imaging modality (CT or MRI), number of readers, and experience of readers; and (d) study outcomes: kappa coefficient ( $\mathrm{k}$ ) with $95 \%$ confidence interval (CI) or standard error.

The quality of the eligible studies was evaluated using the Guidelines for Reporting Reliability and Agreement Studies [19]. Risk of bias regarding the following seven domains was assessed: (a) index test, (b) study subjects, (c) readers, (d) reading process, (e) blinding to reference standard, (f) statistical analysis, and (g) actual numbers of viable/nonviable lesions. Details of the questionnaires regarding each domain are described in Table A2.

The data extraction and quality assessment were independently conducted by the two reviewers, with any disagreements being resolved by consensus. 


\subsection{Statistical Analysis}

Using the $\mathrm{k}$ and $95 \% \mathrm{CI}$ or standard errors reported by the individual eligible studies, the pooled $\mathrm{k}$ with $95 \% \mathrm{CI}$ for overall LR-TR was calculated using the DerSimonian-Laird random effects model [20]. For the available studies, a subgroup analysis was performed according to imaging modality (CT or MRI). Kappa coefficients of $0-0.2,0.21-0.4,0.41-0.6$, $0.61-0.80$, and $0.81-1$ were taken to indicate poor, fair, moderate, substantial, and almost perfect agreement, respectively [21]. Heterogeneity was evaluated using Cochrane's $Q$ test $\left(p<0.10\right.$ indicates substantial heterogeneity) and $I^{2}$ statistics $\left(I^{2}>50 \%\right.$ indicates substantial heterogeneity) [22]. Publication bias was assessed using a funnel plot and Egger test [23].

To explore the causes of any heterogeneity, meta-regression analyses were performed using the covariates of study design (prospective vs. retrospective), underlying liver disease (hepatitis B dominant vs. others), type of treatment (local ablation vs. transarterial treatment), percentage of LR-TR nonviable category ( $\geq 50 \%$ vs. $<50 \%$ ), reader number (two vs. three), reader experience (junior ( $\leq 5$ years of experience)and senior ( $>5$ years of experience) vs. all senior), and statistical methods (unweighted kappa vs. weighted kappa).

R 4.0.3 (R Foundation for Statistical Computing, Vienna, Austria) was used for statistical analysis.

\section{Results}

\subsection{Literature Search}

The systematic search identified 156 studies, and 104 were screened after removal of 52 duplicates (Figure 1). After the exclusion of 90 studies by screening of the title and abstract, and six studies by full-text reviews, eight studies were finally included in this systematic review and meta-analysis [10-17]. Because one study [14] investigating the interreader reliability of both CT and MRI had a population overlapping with that of another MRI study [13], the CT interreader reliability result was separately included from this study.

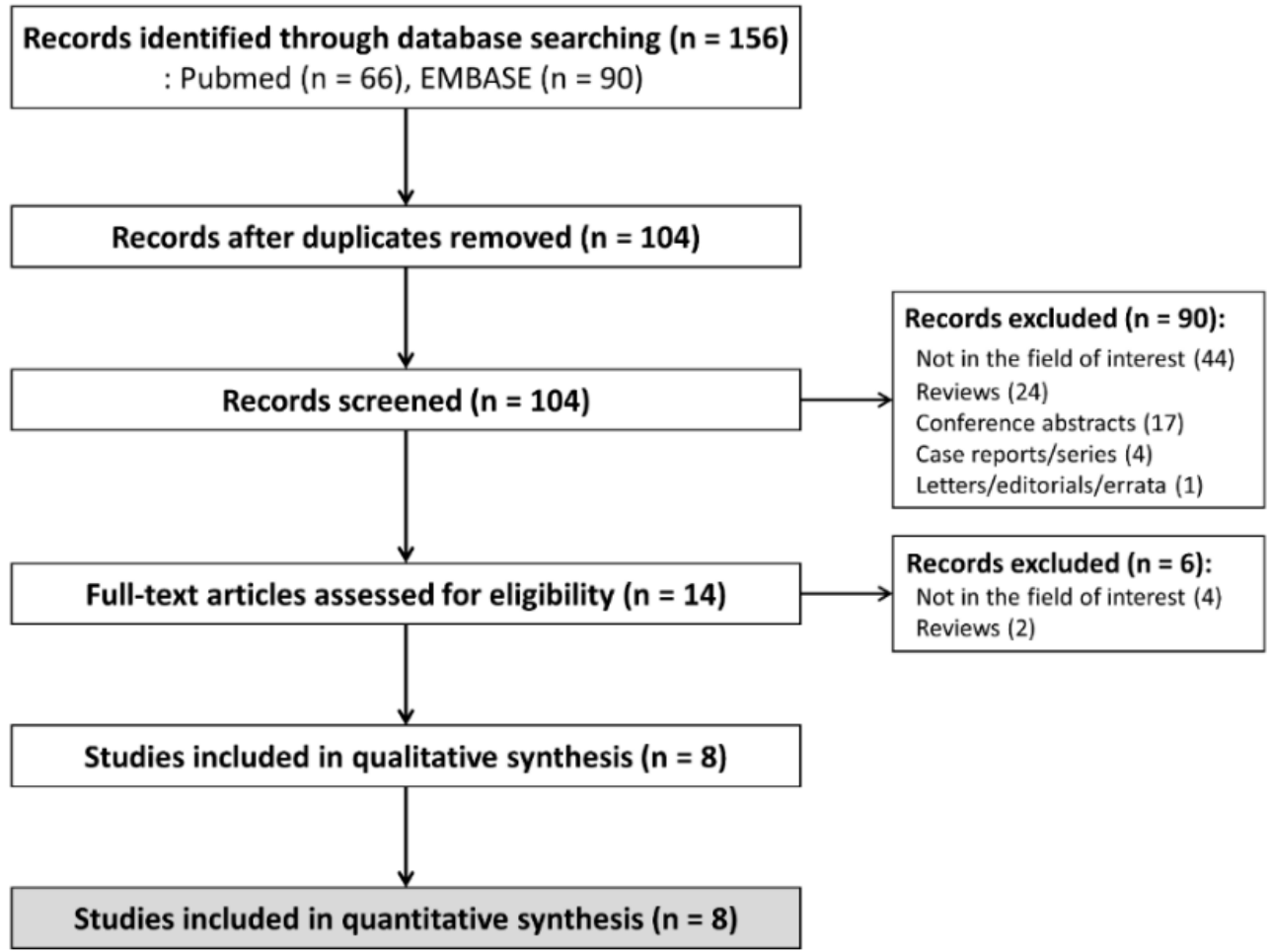

Figure 1. Flow diagram of study selection. 


\subsection{Study Characteristics}

The characteristics of the eligible studies are described in Table 1. One [10] collected the patients prospectively whereas the others [11-17] were retrospective studies. Hepatitis $\mathrm{B}$ was the most common underlying liver disease in four studies, which were all from Eastern countries [13-15,17]. The population was dominated by patients with hepatitis $C$ and alcoholic hepatitis in three studies from Western countries [11,12,16], while one study did not provide information on underlying liver disease [10]. The locoregional treatment was local ablation only (e.g., radiofrequency ablation, microwave ablation, and percutaneous ethanol ablation) in three studies [11,12,17], transarterial treatment (e.g., conventional transarterial chemoembolization, drug-eluting beads transarterial chemoembolization, and transarterial radioembolization) only in one study [16], and both local ablation and transarterial treatment in four studies [10,13-15]. Image analysis was independently performed by two readers in six studies $[10,12-15,17]$ and by three readers in two studies $[11,16]$. The readers were all seniors in five studies $[10-12,15,17]$, whereas both senior and junior readers performed the analysis in three studies $[13,14,16]$.

\subsection{Quality Assessments}

All studies had low risk of bias in more than half of the domains (Figure A1). Four studies $[12,13,15,17]$ had unclear risk of bias regarding the study subjects because it was unclear whether the subjects were consecutively enrolled. Regarding blinding to reference standard, three studies $[10,16,17]$ had unclear risk of bias because they were unclear whether the imaging analysis was blinded to reference standard. Four studies [10-12,17] had high risk of bias in the actual numbers of viable/nonviable lesions due to a lack of information regarding viable HCCs.

\subsection{Interreader Reliability for LR-TR Category Assignment}

In the eight included studies with 851 HCCs, $\mathrm{k}$ ranged from 0.55 to 0.94 , with the pooled $\kappa$ for LR-TR category assignment being 0.70 (95\% CI, 0.58-0.82, Figure 2), indicating substantial interreader reliability. Substantial heterogeneity was observed (Cochrane $\mathrm{Q}$ test: $\left.p<0.001 ; \mathrm{I}^{2}=90.9 \%\right)$ but there was no significant publication bias $(p=0.33$; Figure A2).

\begin{tabular}{l} 
Study \\
\hline Abdel RazeK AAK et al 2020 \\
Chaudhry M et al 2020 \\
Cools KS et al 2020 \\
Kim SW et al 2020 \\
Park Set al 2020 \\
Seo N et al 2020 \\
Shropshire EL et al 2019 \\
Zhang Y et al 2020 \\
\hline Heterogeneity $\left(\mathrm{Q}=77.25, \mathrm{df}=7, \mathrm{P}<0.001 ; \mathrm{I}^{2}=90.9 \%\right)$
\end{tabular}

Figure 2. Forest plot of interreader reliability for the Liver Imaging Reporting and Data System treatment response.

Regarding the imaging modality, the pooled $\mathrm{k}$ values of MRI and CT were 0.71 (95\% CI, $0.53-0.89$, Figure $3 a$ ) and 0.71 ( $95 \%$ CI, $0.65-0.78$, Figure $3 b$ ), respectively, indicating substantial interreader reliability for both MRI and CT. Substantial heterogeneity was noted in the interreader reliability of MRI $\left(p<0.001 ; \mathrm{I}^{2}=93.2 \%\right)$ but not in that of CT $(p=0.39$; $\left.\mathrm{I}^{2}=0 \%\right)$. 
Table 1. Study characteristics.

\begin{tabular}{|c|c|c|c|c|c|c|c|c|c|c|c|c|}
\hline Study & Country & Duration & Study Design & $\begin{array}{c}\text { No. of } \\
\text { Patients }\end{array}$ & M:F & $\begin{array}{l}\text { Age (Years; } \\
\text { Mean } \pm \text { SD) }\end{array}$ & $\begin{array}{c}\text { Underlying Liver Disease } \\
\text { (Number) }\end{array}$ & $\begin{array}{l}\text { No. of } \\
\text { HCCs }\end{array}$ & Treatment & $\begin{array}{l}\text { Modality (Contrast } \\
\text { Agent [If MRI]) }\end{array}$ & $\begin{array}{c}\text { No. of } \\
\text { Readers }\end{array}$ & Reader Experience \\
\hline $\begin{array}{c}\text { Abdel } \\
\text { Razek } \\
\text { AAK et al. } \\
\text { [10] }\end{array}$ & Egypt & $\begin{array}{l}2017.11- \\
2019.01\end{array}$ & Prospective & 93 & 79:14 & $55 \pm 2.6$ & Not available & 112 & $\begin{array}{l}\text { LA (MWA or RFA; 97) TAT } \\
\text { (cTACE; 25) }\end{array}$ & MRI (gadopentetic acid) & 2 & $\begin{array}{l}25 \text { and } 10 \text { years in } \\
\text { liver imaging }\end{array}$ \\
\hline $\begin{array}{l}\text { Cools } \\
\text { KS et al. } \\
\text { [12] }\end{array}$ & USA & $\begin{array}{l}2006.01- \\
2017.12\end{array}$ & Retrospective & 45 & $38: 7$ & $60 \pm 6$ & $\begin{array}{l}\mathrm{HCV}(24) \mathrm{HCV}+\text { alcohol (13) } \\
\text { Alcohol (2) NASH (2) } \\
\text { Autoimmune (1) }\end{array}$ & 59 & LA (MWA or RFA; 59) & $\begin{array}{l}\text { MRI (gadoxetic acid or } \\
\text { gadobenic acid) }\end{array}$ & 2 & 9 years in liver MRI \\
\hline $\begin{array}{l}\text { Kim } \\
\text { SW et al. } \\
\text { [13] }\end{array}$ & Korea & $\begin{array}{l}2015.01- \\
2016.12\end{array}$ & Retrospective & 183 & $133: 50$ & $59.9 \pm 10.8$ & $\begin{array}{c}\text { HBV (111) Alcohol (34) HCV (25) } \\
\text { Others (13) }\end{array}$ & 183 & $\begin{array}{l}\text { TAT (cTACE or } \\
\text { DEB-TACE; 137) LA (RFA; } \\
\text { 42) LA + TAT (4) }\end{array}$ & MRI (gadoxetic acid) & 2 & $\begin{array}{l}7 \text { and } 5 \text { years in } \\
\text { liver MRI }\end{array}$ \\
\hline $\begin{array}{c}\text { Park } \\
\text { S et al. } \\
\text { [14] }\end{array}$ & Korea & $\begin{array}{l}2014.01- \\
2017.12\end{array}$ & Retrospective & 138 & 119:19 & $58 \pm 9$ & $\begin{array}{l}\text { HBV (111) HCV (13) Alcohol (6) } \\
\text { Others (8) }\end{array}$ & 138 & $\begin{array}{l}\text { TAT (cTACE, DEB-TACE, } \\
\text { or TARE; 98) LA (RFA or } \\
\text { PEIT; 18) TAT + LA (22) }\end{array}$ & $\begin{array}{l}\mathrm{CT} \text { and MRI (gadoxetic } \\
\text { acid) }\end{array}$ & 2 & $\begin{array}{l}7 \text { and } 5 \text { years in } \\
\text { liver imaging }\end{array}$ \\
\hline $\begin{array}{l}\text { Seo } \\
\text { N et al. } \\
\text { [15] }\end{array}$ & Korea & $\begin{array}{l}2007.01- \\
2014.12\end{array}$ & Retrospective & $\begin{array}{c}114 \\
\text { (CT, 113; } \\
\text { MRI, 53) }\end{array}$ & $96: 18$ & $54 \pm 6.9$ & $\begin{array}{l}\text { HBV (100) HCV (8) Alcohol (2) } \\
\text { Others (4) }\end{array}$ & $\begin{array}{c}206 \\
(C T, 203 ; \\
\text { MRI, 84) }\end{array}$ & $\begin{array}{c}\text { TAT (cTACE or } \\
\text { DEB-TACE; 168) LA (RFA; } \\
\text { 34) TAT + LA (4) }\end{array}$ & $\begin{array}{l}\mathrm{CT} \text { and/or MRI } \\
\text { (gadoxetic acid or } \\
\text { gadoteric acid) }\end{array}$ & 2 & $\begin{array}{l}17 \text { and } 16 \text { years in } \\
\text { liver MRI }\end{array}$ \\
\hline $\begin{array}{l}\text { Shropshire } \\
\text { EL et al. } \\
\text { [16] }\end{array}$ & USA & $\begin{array}{l}2006- \\
2016\end{array}$ & Retrospective & $\begin{array}{l}45 \text { (CT, 24; } \\
\text { MRI, 21) }\end{array}$ & $32: 13$ & $57.1 \pm 8.2$ & $\begin{array}{c}\text { HCV (22) HCV + alcohol (8) } \\
\text { NASH (6) Alcohol (2) AIH (2) } \\
\text { NASH + Alcohol (1) HBV (1) } \\
\text { Glycogen storage disease (1) } \\
\text { Others (2) }\end{array}$ & 63 & TAT (cTACE; 63) & $\begin{array}{l}\text { CT or MRI (gadoxetic } \\
\text { acid or gadobenic acid) }\end{array}$ & 3 & $\begin{array}{l}17 \text { and } 11 \text { years in } \\
\text { abdominal MRI }\end{array}$ \\
\hline $\begin{array}{c}\text { Zhang } \\
\text { Y et al. } \\
\text { [17] }\end{array}$ & China & $\begin{array}{l}2010.01- \\
2016.12\end{array}$ & Retrospective & 40 & $35: 5$ & $60.3 \pm 10.4$ & HBV (32) HCV (2) Others (6) & 40 & LA (RFA; 40) & $\mathrm{CT}$ & 2 & $\begin{array}{c}8 \text { and } 7 \text { years in } \\
\text { liver imaging }\end{array}$ \\
\hline
\end{tabular}

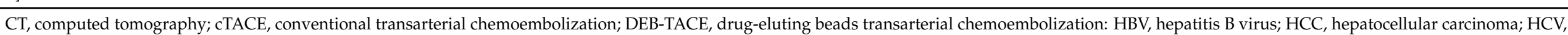

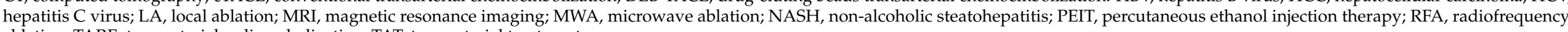
ablation; TARE, transarterial radioembolization; TAT, transarterial treatment. 


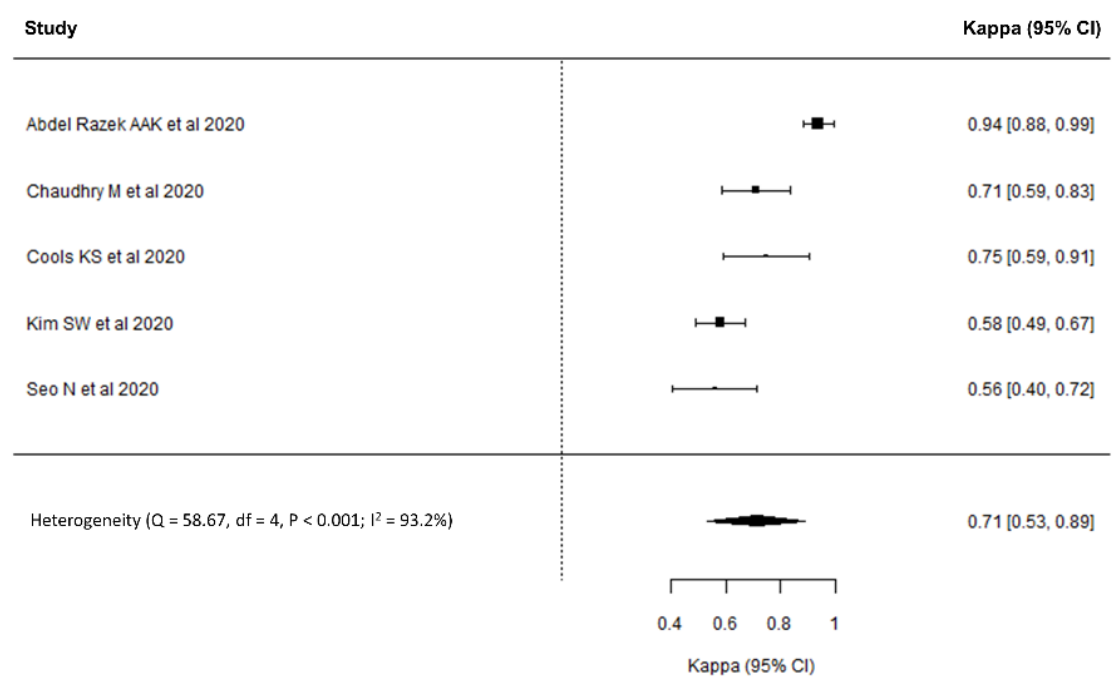

(a)

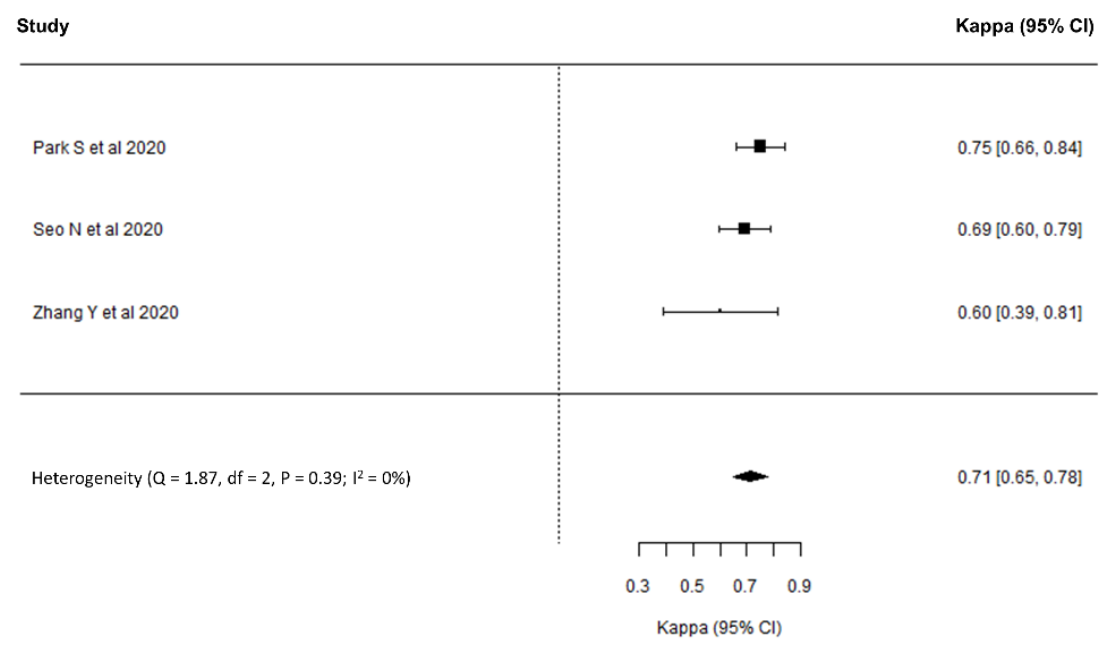

(b)

Figure 3. Forest plots of interreader reliability in the subgroups of studies using MRI (a) and CT (b).

\subsection{Meta-Regression Analysis}

The results of the meta-regression analyses are described in Table 2. Study design $(p<0.001)$ and type of treatment $(p=0.02)$ were significantly associated with study heterogeneity: prospective studies had a significantly higher pooled $\kappa$ than retrospective studies (0.94 vs. 0.66), and $\mathrm{k}$ for assessments of LR-TR for HCC after local ablation was significantly higher than that after transarterial treatment ( 0.70 vs. 0.55$)$. Other covariates were not significantly associated with study heterogeneity.

Table 2. Meta-regression analyses for interreader reliability in diagnosis using the Liver Imaging Reporting and Data System (LI-RADS) treatment response algorithm (LR-TR).

\begin{tabular}{cccccc}
\hline Covariate & Subgroup & Number of Studies & Estimates & 95\% CI & $p$-Value \\
\hline \multirow{2}{*}{ Study design } & Prospective & 1 & 0.94 & $0.88-0.99$ & $<0.001$ \\
\cline { 2 - 7 } & Retrospective & 7 & 0.66 & $0.60-0.73$ & $0.58-0.75$ \\
\hline \multirow{2}{*}{ Underlying liver disease } & HBV dominant & 4 & 0.67 & 0.49 \\
\cline { 2 - 7 } & Others & 4 & 0.74 & $0.54-0.94$ & $0.62-0.79$ \\
\hline \multirow{2}{*}{ Type of treatment } & Local ablation & 3 & 0.70 & 0.02 \\
\cline { 2 - 7 } & Transarterial treatment & 1 & 0.55 & $0.45-0.65$ & \\
\hline
\end{tabular}


Table 2. Cont.

\begin{tabular}{|c|c|c|c|c|c|}
\hline Covariate & Subgroup & Number of Studies & Estimates & $95 \% \mathrm{CI}$ & $p$-Value \\
\hline \multirow{2}{*}{$\%$ of LR-TR nonviable } & $\geq 50 \%$ & 5 & 0.72 & $0.55-0.90$ & 0.63 \\
\hline & $<50 \%$ & 3 & 0.67 & $0.55-0.78$ & \\
\hline \multirow{2}{*}{ Reader number } & 2 (Cohen's kappa) & 6 & 0.73 & $0.59-0.86$ & 0.46 \\
\hline & 3 (Fleiss kappa) & 2 & 0.63 & $0.47-0.78$ & \\
\hline \multirow{2}{*}{ Reader experience } & Junior + Senior & 3 & 0.63 & $0.50-0.75$ & 0.22 \\
\hline & All senior & 5 & 0.75 & $0.61-0.89$ & \\
\hline \multirow{2}{*}{ Statistical methods } & Unweighted kappa & 5 & 0.66 & $0.58-0.74$ & 0.39 \\
\hline & Weighed Kappa & 3 & 0.76 & $0.54-0.98$ & \\
\hline
\end{tabular}

\section{Discussion}

Our study found that the pooled interreader reliability of LR-TR was substantial ( $\kappa, 0.70 ; 95 \% \mathrm{CI}, 0.58-0.82)$, and that the interreader reliability of $\mathrm{CT}$ was very similar to that of MRI (CT, k, 0.71 (95\% CI, 0.53-0.89) vs. MRI, $\kappa, 0.71$ (95\% CI, 0.65-0.78)). Study design (prospective vs. retrospective, $p<0.001$ ) and the type of treatment (local ablation vs. transarterial treatment, $p=0.02$ ) were significant factors affecting study heterogeneity.

LR-TR showed substantial interreader reliability in the assessment of treatment response after locoregional treatment. This interreader reliability of LR-TR was comparable to reported values for other response assessment criteria such as that of the European Association for the Study of the Liver (EASL; $\kappa, 0.69-0.76$ ) and the modified version of the Response Evaluation Criteria in Solid Tumors (mRECIST; $k$, 0.67-0.78) [24]. Although LR-TR, EASL, and mRECIST all use arterial-phase hyperenhancement for viability assessment, the major difference in LR-TR is the use of other imaging features including washout and enhancement similar to pre-treatment. Therefore, the interpretation of LR-TR is prone to being more complex and subjective than that of EASL or mRECIST [13,15]. Nevertheless, the strictly standardized definition of viable tumor (i.e., nodular, mass-like, or thick irregular tissue with arterial-phase hyperenhancement, washout, or enhancement similar to pre-treatment) and the reservoir for lesions with indeterminate certainty of viability (i.e., the equivocal category) in LR-TR might explain the comparable results for interreader reliability between LR-TR, EASL, and mRECIST.

Several previous studies reported conflicting results when determining the optimal imaging modality [25-28], and in terms of reliability, it is questionable which imaging modality is appropriate for treatment response assessment in HCC after locoregional treatment. According to our study, both CT and MRI showed substantial ( $\kappa, 0.71$ both in CT and MRI) interreader reliability without a significant difference between them. A plausible explanation for the comparable interreader reliability in this study can be found in the advantages and disadvantages of each imaging modality. For example, in the interpretation of CT after transarterial chemoembolization (TACE), hyperdense lipiodol accumulation precludes accurate assessment by directly obscuring enhancement in the viable portion or by indirectly obscuring it through beam-hardening artifacts [29,30], thus potentially decreasing the reliability of the imaging interpretation. By contrast, iodized oil hardly masks viable HCC on MRI [26,27,31]. However, particularly with the use of gadoxetic acid as a contrast agent, the advantages of MRI can be offset by the weak arterial-phase hyperenhancement due to the relatively small contrast dose and strict washout criteria that are restricted to the portal venous phase according to the current LI-RADS [32].

In the meta-regression analysis, the type of treatment was one of the causes of substantial heterogeneity. Although the current LR-TR was designed to assess treated HCC regardless of the type of locoregional treatment, the post-treatment imaging features are specific to each treatment and may therefore cause differences in interreader reliability. Indeed, interreader reliability was significantly higher in local ablation-treated HCC than 
in TACE-treated HCC ( $\kappa, 0.70$ vs. $0.55 ; p=0.02)$. As we discussed above, hyperdense lipiodol accumulation after TACE may result in uncertainty about whether a residual viable tumor portion is present or not, and may lead to interreader variability in the treatment assessment, particularly when using CT. In addition, tumor heterogeneity caused by partial lipiodol uptake or necrosis in TACE-treated HCC might result in lower interreader reliability than that found for local ablation-treated HCC [33]. Another potential cause of study heterogeneity was the study design. In fact, one prospective study [10] showed significantly higher interreader reliability than the other eligible studies that retrospectively enrolled patients $(\kappa, 0.94$ vs. $0.66 ; p<0.001)$, and this higher interreader reliability in the prospective study might be explained by the uniform MRI protocol and image analysis [10]. However, our results should be interpreted with caution because the meta-regression analyses were performed using only a small number of studies, numbering eight in total.

Our study has several limitations. First, substantial study heterogeneity was noted, and therefore the single meta-analytic summary estimates may not fully cover the results of the individual studies. To overcome the heterogeneity, we performed a subgroup analysis and meta-regression analyses. Second, locoregional treatment using EBRT could not be evaluated in our study because of a lack of available studies evaluating the interreader reliability of LR-TR EBRT. Considering the slow reduction in size and devascularization after EBRT [34], the interreader reliability of LR-TR after EBRT might differ from that after local ablation or TACE. Third, although our study focused on the interreader reliability of LR-TR, the evaluation of diagnostic performance is also important. Therefore, future study would be necessary to evaluate the diagnostic performance as well as interreader reliability of LR-TR compared with EASL, or mRECIST.

In conclusion, CT/MRI LR-TR v2017 had substantial interreader reliability regardless of the imaging modality. Substantial study heterogeneity was noted, which was significantly associated with the study design and type of treatment. Because of the presence of substantial study heterogeneity, values for the LR-TR interreader reliability reported in the published literature should be interpreted carefully.

Author Contributions: Conceptualization, S.H.C. and S.Y.K.; methodology, D.W.K. and S.H.C.; formal analysis, S.H.C. and J.S.L.; investigation, D.W.K. and S.H.C.; resources, S.Y.K., S.J.L., and J.H.B.; data curation, D.W.K. and S.H.C.; writing—original draft preparation, D.W.K.; writing-review and editing, S.H.C., S.Y.K., and S.J.L.; supervision, J.H.B.; project administration, S.H.C.; funding acquisition, S.H.C. All authors have read and agreed to the published version of the manuscript.

Funding: This work was supported by a National Research Foundation of Korea (NRF) grant funded by the Korean government (MSIT) (Grant No. NRF-2019R1G1A1099743).

Institutional Review Board Statement: Not applicable.

Informed Consent Statement: Not applicable.

Conflicts of Interest: The authors declare no conflict of interest.

\section{Appendix A}

Table A1. Search queries for MEDLINE and EMBASE.

\begin{tabular}{cc}
\hline No. & Search Query for MEDLINE \\
\hline$\# 1$ & $((($ liver neoplasms[MeSH Terms]) OR (Liver[MeSH Terms]))) AND (radiology information systems[MeSH Terms]) \\
\hline$\# 2$ & (LI-RADS[Text Word]) OR (“liver imaging reporting”[Text Word]) \\
\hline$\# 3$ & (treatment[Text Word]) OR (response[Text Word]) \\
\hline$\# 4$ & $\# 1$ OR \#2 \\
\hline$\# 5$ & $\# 3$ AND \#4 \\
\hline$\# 6$ & LR-TR[Text Word] \\
\hline$\# 7$ & $\# 5$ OR \#6
\end{tabular}


Table A1. Cont.

\begin{tabular}{|c|c|}
\hline No. & Search Query for MEDLINE \\
\hline$\# 8$ & $\begin{array}{c}(((\text { magnetic resonance imaging[MeSH Terms] }) \text { OR ("magnetic resonanc" } \\
\text { (MR[Text Word] })\end{array}$ \\
\hline \#9 & ((x ray tomography, computed[MeSH Terms]) OR (“computed tomograph*”[Text Word])) OR (CT[Text Word]) \\
\hline$\# 10$ & \#8 OR \#9 \\
\hline$\# 11$ & \#7 AND \#10 \\
\hline \#12 & \#11 AND English[Lang] \\
\hline No. & Search Query for EMBASE \\
\hline$\# 1$ & 'liver imaging reporting and data system' / exp OR 'liver imaging reporting and data system' \\
\hline \#2 & ‘li-rads':ab,ti,kw OR ‘liver imaging reporting':ab,ti,kw \\
\hline \#3 & 'treatment' / exp OR treatment OR 'response' / exp OR response \\
\hline \#4 & \#1 OR \#2 \\
\hline \#5 & \#3 AND \#4 \\
\hline \#6 & 'lr-tr’ \\
\hline$\# 7$ & \#5 OR \#6 \\
\hline$\# 8$ & 'magnetic resonanc's':ab,ti,kw OR mri:ab,ti,kw OR mr:ab,ti,kw \\
\hline \#9 & 'computed tomograph':ab,ti,kw OR ct:ab,ti,kw \\
\hline$\# 10$ & \#8 OR \#9 \\
\hline$\# 11$ & \#7 AND \#10 \\
\hline$\# 12$ & \#11 AND [english]/lim \\
\hline
\end{tabular}

Table A2. Questionnaires for quality assessments of the eligible study.

\begin{tabular}{cc}
\hline Domain & Questionnaires \\
\hline Index test & $\begin{array}{c}\text { Was information of CT and MRI examination explicitly described? } \\
\text { Were methods of CT and MRI examination applicable? }\end{array}$ \\
Study subject & $\begin{array}{c}\text { Was a consecutive or random sample of patients enrolled? } \\
\text { Was a case-control design avoided? } \\
\text { Did the study avoid inappropriate exclusion? }\end{array}$ \\
\hline Readers & Was information (e.g., number and experiences of readers) explicitly described? \\
Were readers representative for general reading practice?
\end{tabular}




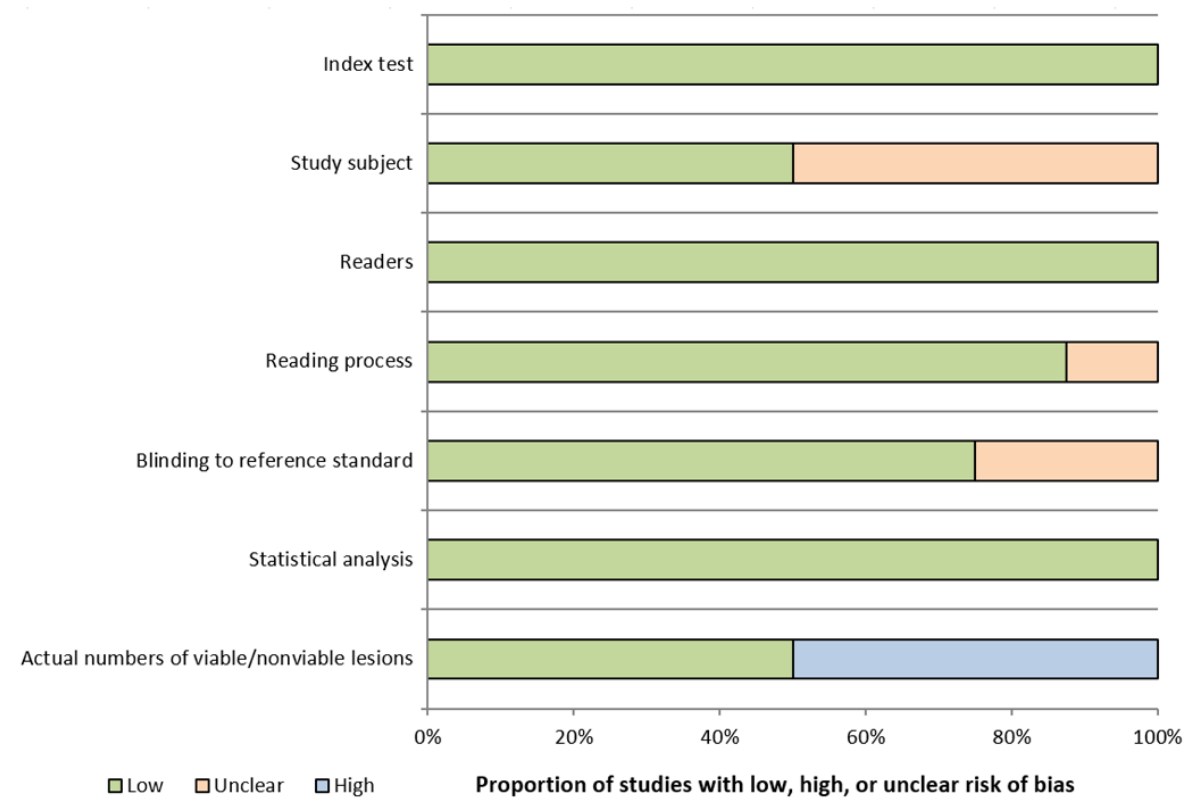

Figure A1. Quality assessment of the eligible studies.

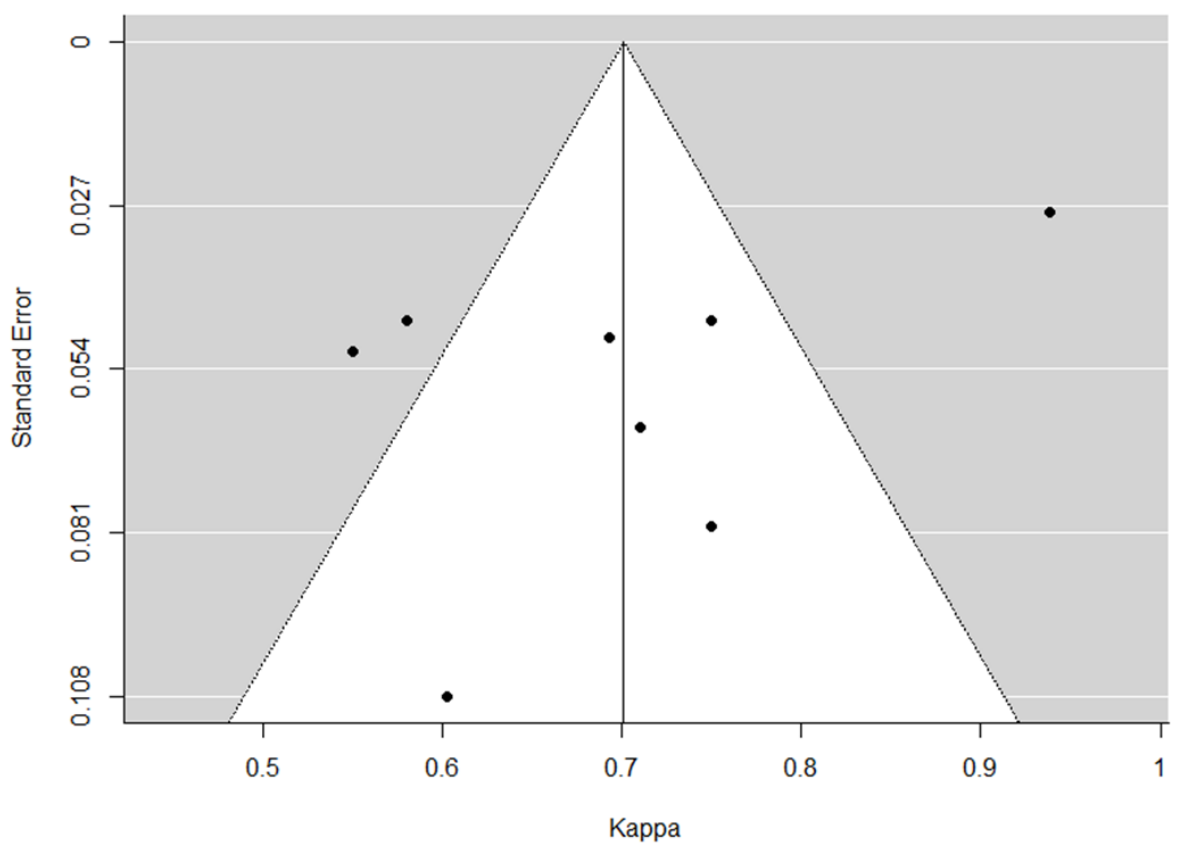

Figure A2. Funnel plot for evaluation of publication bias.

\section{References}

1. Bray, F.; Ferlay, J.; Soerjomataram, I.; Siegel, R.L.; Torre, L.A.; Jemal, A. Global cancer statistics 2018: GLOBOCAN estimates of incidence and mortality worldwide for 36 cancers in 185 countries. CA Cancer J. Clin. 2018, 68, 394-424. [CrossRef] [PubMed]

2. Ghouri, Y.A.; Mian, I.; Rowe, J.H. Review of hepatocellular carcinoma: Epidemiology, etiology, and carcinogenesis. J. Carcinog. 2017, 16, 1. [CrossRef]

3. Cescon, M.; Cucchetti, A.; Ravaioli, M.; Pinna, A.D. Hepatocellular carcinoma locoregional therapies for patients in the waiting list. Impact on transplantability and recurrence rate. J. Hepatol. 2013, 58, 609-618. [CrossRef]

4. Heimbach, J.K.; Kulik, L.M.; Finn, R.S.; Sirlin, C.B.; Abecassis, M.M.; Roberts, L.R.; Zhu, A.X.; Murad, M.H.; Marrero, J.A. AASLD guidelines for the treatment of hepatocellular carcinoma. Hepatology 2018, 67, 358-380. [CrossRef] [PubMed] 
5. Lee, M.W.; Raman, S.S.; Asvadi, N.H.; Siripongsakun, S.; Hicks, R.M.; Chen, J.; Worakitsitisatorn, A.; McWilliams, J.; Tong, M.J.; Finn, R.S.; et al. Radiofrequency ablation of hepatocellular carcinoma as bridge therapy to liver transplantation: A 10-year intention-to-treat analysis. Hepatology 2017, 65, 1979-1990. [CrossRef] [PubMed]

6. Lu, D.S.; Yu, N.C.; Raman, S.S.; Lassman, C.; Tong, M.J.; Britten, C.; Durazo, F.; Saab, S.; Han, S.; Finn, R.; et al. Percutaneous radiofrequency ablation of hepatocellular carcinoma as a bridge to liver transplantation. Hepatology 2005, 41, 1130-1137. [CrossRef]

7. Ho, M.H.; Yu, C.Y.; Chung, K.P.; Chen, T.W.; Chu, H.C.; Lin, C.K.; Hsieh, C.B. Locoregional therapy-induced tumor necrosis as a predictor of recurrence after liver transplant in patients with hepatocellular carcinoma. Ann. Surg. Oncol. 2011, 18, 3632-3639. [CrossRef] [PubMed]

8. Allard, M.A.; Sebagh, M.; Ruiz, A.; Guettier, C.; Paule, B.; Vibert, E.; Cunha, A.S.; Cherqui, D.; Samuel, D.; Bismuth, H.; et al. Does pathological response after transarterial chemoembolization for hepatocellular carcinoma in cirrhotic patients with cirrhosis predict outcome after liver resection or transplantation? J. Hepatol. 2015, 63, 83-92. [CrossRef]

9. American College of Radiology. Liver Imaging Reporting and Data System (LI-RADS). Available online: https:/ / www.acr.org/ Clinical-Resources/Reporting-and-Data-Systems/LI-RADS/CT-MRI-LI-RADS-v2017 (accessed on 11 November 2020).

10. Abdel Razek, A.A.K.; El-Serougy, L.G.; Saleh, G.A.; Shabana, W.; Abd El-Wahab, R. Reproducibility of LI-RADS treatment response algorithm for hepatocellular carcinoma after locoregional therapy. Diagn. Inter. Imaging 2020, 101, 547-553. [CrossRef]

11. Chaudhry, M.; McGinty, K.A.; Mervak, B.; Lerebours, R.; Li, C.; Shropshire, E.; Ronald, J.; Commander, L.; Hertel, J.; Luo, S.; et al. The LI-RADS Version 2018 MRI treatment response algorithm: Evaluation of ablated hepatocellular carcinoma. Radiology 2020, 294, 320-326. [CrossRef] [PubMed]

12. Cools, K.S.; Moon, A.M.; Burke, L.M.B.; McGinty, K.A.; Strassle, P.D.; Gerber, D.A. Validation of the Liver Imaging Reporting and Data System Treatment Response Criteria After Thermal Ablation for Hepatocellular Carcinoma. Liver Transplant. 2020, 26, 203-214. [CrossRef]

13. Kim, S.W.; Joo, I.; Kim, H.C.; Ahn, S.J.; Kang, H.J.; Jeon, S.K.; Lee, J.M. LI-RADS treatment response categorization on gadoxetic acid-enhanced MRI: Diagnostic performance compared to mRECIST and added value of ancillary features. Eur. Radiol. 2020, 30, 2861-2870. [CrossRef] [PubMed]

14. Park, S.; Joo, I.; Lee, D.H.; Bae, J.S.; Yoo, J.; Kim, S.W.; Lee, J.M. Diagnostic Performance of LI-RADS Treatment Response Algorithm for Hepatocellular Carcinoma: Adding Ancillary Features to MRI Compared with Enhancement Patterns at CT and MRI. Radiology 2020, 296, 554-561. [CrossRef] [PubMed]

15. Seo, N.; Kim, M.S.; Park, M.S.; Choi, J.Y.; Do, R.K.G.; Han, K.; Kim, M.J. Evaluation of treatment response in hepatocellular carcinoma in the explanted liver with Liver Imaging Reporting and Data System version 2017. Eur. Radiol. 2020, 30, 261-271. [CrossRef]

16. Shropshire, E.L.; Chaudhry, M.; Miller, C.M.; Allen, B.C.; Bozdogan, E.; Cardona, D.M.; King, L.Y.; Janas, G.L.; Do, R.K.; Kim, C.Y.; et al. LI-RADS treatment response algorithm: Performance and diagnostic accuracy. Radiology 2019, 292, 226-234. [CrossRef] [PubMed]

17. Zhang, Y.; Wang, J.; Li, H.; Zheng, T.; Jiang, H.; Li, M.; Song, B. Performance of LI-RADS version 2018 CT treatment response algorithm in tumor response evaluation and survival prediction of patients with single hepatocellular carcinoma after radiofrequency ablation. Ann. Transl. Med. 2020, 8. [CrossRef] [PubMed]

18. Liberati, A.; Altman, D.G.; Tetzlaff, J.; Mulrow, C.; Gøtzsche, P.C.; Ioannidis, J.P.; Clarke, M.; Devereaux, P.J.; Kleijnen, J.; Moher, D. The PRISMA statement for reporting systematic reviews and meta-analyses of studies that evaluate healthcare interventions: Explanation and elaboration. BMJ 2009, 339, b2700. [CrossRef]

19. Kottner, J.; Audigé, L.; Brorson, S.; Donner, A.; Gajewski, B.J.; Hróbjartsson, A.; Roberts, C.; Shoukri, M.; Streiner, D.L. Guidelines for Reporting Reliability and Agreement Studies (GRRAS) were proposed. J. Clin. Epidemiol. 2011, 64, 96-106. [CrossRef] [PubMed]

20. DerSimonian, R.; Laird, N. Meta-analysis in clinical trials. Control. Clin. Trials 1986, 7, 177-188. [CrossRef]

21. Landis, J.R.; Koch, G.G. The measurement of observer agreement for categorical data. Biometrics 1977, 33, 159-174. [CrossRef]

22. Higgins, J.P.; Thompson, S.G.; Deeks, J.J.; Altman, D.G. Measuring inconsistency in meta-analyses. BMJ 2003, 327, 557-560. [CrossRef]

23. Egger, M.; Davey Smith, G.; Schneider, M.; Minder, C. Bias in meta-analysis detected by a simple, graphical test. BMJ 1997, 315, 629-634. [CrossRef] [PubMed]

24. Donati, O.F.; Do, R.K.; Hötker, A.M.; Katz, S.S.; Zheng, J.; Moskowitz, C.S.; Beattie, C.; Brown, K.T. Interreader and inter-test agreement in assessing treatment response following transarterial embolization for hepatocellular carcinoma. Eur. Radiol. 2015, 25, 2779-2788. [CrossRef] [PubMed]

25. Yoon, J.H.; Lee, E.J.; Cha, S.S.; Han, S.S.; Choi, S.J.; Juhn, J.R.; Kim, M.H.; Lee, Y.J.; Park, S.J. Comparison of gadoxetic acid-enhanced MR imaging versus four-phase multi-detector row computed tomography in assessing tumor regression after radiofrequency ablation in subjects with hepatocellular carcinomas. J. Vasc. Interv. Radiol. 2010, 21, 348-356. [CrossRef]

26. Kloeckner, R.; Otto, G.; Biesterfeld, S.; Oberholzer, K.; Dueber, C.; Pitton, M.B. MDCT versus MRI assessment of tumor response after transarterial chemoembolization for the treatment of hepatocellular carcinoma. Cardiovasc. Interv. Radiol. 2010, 33, 532-540. [CrossRef] 
27. Shim, J.H.; Han, S.; Shin, Y.M.; Yu, E.; Park, W.; Kim, K.M.; Lim, Y.S.; Lee, H.C. Optimal measurement modality and method for evaluation of responses to transarterial chemoembolization of hepatocellular carcinoma based on enhancement criteria. J. Vasc. Interv. Radiol. 2013, 24, 316-325. [CrossRef]

28. Watanabe, H.; Kanematsu, M.; Goshima, S.; Yoshida, M.; Kawada, H.; Kondo, H.; Moriyama, N. Is gadoxetate disodium-enhanced MRI useful for detecting local recurrence of hepatocellular carcinoma after radiofrequency ablation therapy? AJR Am. J. Roentgenol. 2012, 198, 589-595. [CrossRef]

29. Kim, H.C.; Kim, A.Y.; Han, J.K.; Chung, J.W.; Lee, J.Y.; Park, J.H.; Choi, B.I. Hepatic arterial and portal venous phase helical CT in patients treated with transcatheter arterial chemoembolization for hepatocellular carcinoma: Added value of unenhanced images. Radiology 2002, 225, 773-780. [CrossRef] [PubMed]

30. Kim, Y.S.; Rhim, H.; Lim, H.K.; Park, C.K.; Lee, W.J.; Do, Y.S.; Cho, J.W. Completeness of treatment in hepatocellular carcinomas treated with image-guided tumor therapies: Evaluation of positive predictive value of contrast-enhanced CT with histopathologic correlation in the explanted liver specimen. J. Comput. Assist. Tomogr. 2006, 30, 578-582. [CrossRef] [PubMed]

31. Hunt, S.J.; Yu, W.; Weintraub, J.; Prince, M.R.; Kothary, N. Radiologic monitoring of hepatocellular carcinoma tumor viability after transhepatic arterial chemoembolization: Estimating the accuracy of contrast-enhanced cross-sectional imaging with histopathologic correlation. J. Vasc. Interv. Radiol. 2009, 20, 30-38. [CrossRef] [PubMed]

32. Chernyak, V.; Fowler, K.J.; Heiken, J.P.; Sirlin, C.B. Use of gadoxetate disodium in patients with chronic liver disease and its implications for liver imaging reporting and data system (LI-RADS). J. Magn. Reson Imaging 2019, 49, 1236-1252. [CrossRef] [PubMed]

33. Lim, H.S.; Jeong, Y.Y.; Kang, H.K.; Kim, J.K.; Park, J.G. Imaging features of hepatocellular carcinoma after transcatheter arterial chemoembolization and radiofrequency ablation. AJR Am. J. Roentgenol. 2006, 187, W341-W349. [CrossRef] [PubMed]

34. Mastrocostas, K.; Jang, H.J.; Fischer, S.; Dawson, L.A.; Munoz-Schuffenegger, P.; Sapisochin, G.; Kim, T.K. Imaging poststereotactic body radiation therapy responses for hepatocellular carcinoma: Typical imaging patterns and pitfalls. Abdom. Radiol. N. Y. 2019, 44, 1795-1807. [CrossRef] [PubMed] 